\title{
Different types of mechanical vibration application on EMG response and strength performance
}

\author{
Aler R. Almeida ${ }^{1}$ (D), Marcos D. M. Drummond ${ }^{1}$ (D), Leszek A. Szmuchrowski ${ }^{1}$ (D), \\ Gustavo F. Pedrosa $^{2}$ (D), Bruno P. Couto ${ }^{1}$ \\ ${ }^{1}$ Universidade Federal de Minas Gerais, Belo Horizonte, $M G$, Brazil; ${ }^{2}$ Força Aérea Brasileira, \\ Centro de Instrução e Adaptação da Aeronáutica, Belo Horizonte, MG, Brazil.
}

Associate Editor: Almir Vieira Dibai Filho (D), Universidade Federal do Maranhão, São Luis, MA,

Brazil. E-mail: dibaifilho@gmail.com.

\begin{abstract}
Aim: The present study aimed to compare the strength performance and the neuromuscular activity during one maximum repetition test (1RM), and the maximum voluntary isometric contractions (MVIC) performed with whole-body vibration (WBV), local vibration (LV), and no vibration (NV). Methods: The sample consisted of 15 males, experienced in strength training for at least 6 months, which performed all strength tests in the barbell curl exercise across randomized trials on the following conditions: NV, WBV, and LV. During all tests, the normalized root means square values of the electromyographic signals $\left(\mathrm{EMG}_{\mathrm{RMS}}\right)$ of the biceps brachii and brachioradialis were recorded and compared between the conditions. The one-way ANOVAs with repeated measures were used to compare the results of 1RM and MVIC tests and the normalized $\mathrm{EMG}_{\mathrm{RMS}}$ between the conditions. When necessary, a post hoc ScottKnott test was used to identify the differences reported in the ANOVAs. The significance level adopted was $\alpha<0.05$. Results: The $\mathrm{EMG}_{\mathrm{RMS}}$ response of the biceps brachii and brachioradialis muscles during the 1RM and MVIC tests presented significantly higher values at LV compared to WBV, and NV ( $\mathrm{p}<0.001)$. The 1RM tests, and the MVIC results were similar between conditions $(p=0.9803 ; p=0.061$, respectively). Conclusion: These results indicate that the application of MV was not sufficient to increase strength performance.
\end{abstract}

Keywords: muscle spindle, electromyography, strength training, one maximum repetition test.

\section{Introduction}

In the search of incrementing gains in muscle strength, researchers have been using mechanical vibration (MV) in their studies protocols ${ }^{1-6}$. However, the outcomes of applying MV to improve muscle strength are still controversial $^{7,8}$. This incongruence, at least in part, seems to be due to different combinations of mechanical parameters, as the time of exposure, frequency, and amplitude of MV. Variations on either MV frequency or amplitude may modify the vibratory impulse accelerations applied to the body ${ }^{9-11}$. This fact may alter the neurophysiological response to $\mathrm{MV}^{10}$. In addition, two types of MV have been the focus of the investigation; the whole-body vibration $(\mathrm{WBV})^{12}$, and local vibration $(\mathrm{LV})^{13}$. However, no study has yet compared the neuromuscular response by using both types of MV.

The WBV may be attained with a person standing on a vibration platform while performing an exercise, such as jumps and squats ${ }^{14}$ or even in elbow flexion exercises ${ }^{14}$. The MV from the platform is transmitted along the body, activating the alpha-motorneuron as a response to stretch reflex via muscle spindles ${ }^{15}$, improving strength genera- tion to higher levels that, probably, would not be achieved without vibration in a similar stimulus ${ }^{16}$. However, during the vibration transmission along the body, a dissipation of the vibratory impulse may occur reducing its effects ${ }^{17}$. Thus, muscle groups located nearby the vibratory source tend to present greater effects on strength development in comparison to further muscle groups ${ }^{12}$. Therefore, the use of WBV by a vibration platform may not be efficient when the muscle strength increase is wanted for upper limbs. However, exercises for upper limbs performed with WBV can be prescribed by coaches in sports and fitness, such as biceps curl, rows, and other exercises with barbell and dumbbell. Nevertheless, the possible attenuation of the vibratory impulse between the source of the vibration and the target muscle in strength performance has yet to be investigated.

Aiming to minimize the vibratory impulse loss, the LV seems to be an interesting alternative ${ }^{7,13,18}$. The LV occurs when the MV is applied directly on the muscle bel$1 y^{13}$, on the tendon of the target muscle ${ }^{12}$, on the weight to be lifted ${ }^{19}$, or yet, in the direction of the resultant force of the contracting muscles $8,20,21$. In this last case, the vibratory impulse generates small muscle stretches that may 
elicit greater muscle spindles stimulation and perhaps, greater muscle strength development in comparison to other types of $\mathrm{MV}^{8}$.

The MVs, applied by $\mathrm{LV}^{22}$, and $\mathrm{WBV}^{23}$, may increase the excitability of the neuromuscular sensors by the tonic vibration reflex $^{22}$ and increasing the electric muscle activity ${ }^{23}$. The registration and analysis of the amplitude of the electromyographic signal $\left(\mathrm{EMG}_{\text {amplitude }}\right)$ may contribute to the understanding of the neurophysiological responses in both conditions, LV, and WBV. The $\mathrm{EMG}_{\text {amplitude }}$ response represents the degree of muscle activation and, at least in part, the recruitment of motor units $^{24}$. Nevertheless, no studies were found comparing the effects of applying WBV, and LV on the resultant force direction on isometric and dynamic strength response of upper limbs. In addition, it is not yet known what would be the strength response by the one maximum repetition test (1RM), or by the maximum voluntary isometric contractions (MVIC) test between the conditions LV and WBV.

Some studies adopt the result of the 1RM test, performed without vibrations, as a reference for the prescription of training intensity with and without the $M^{25}$. Therefore, the weight to be used during the exercises to which the volunteers will be submitted by MV is based on percentage values of the maximum weight displaced in the $1 \mathrm{RM}$ test without vibration. As the application of MV during the 1RM test may influence the result of this test ${ }^{25}$, the intensity of strength training performed with vibration prescribed based on the 1RM test performed without vibration may be underestimated, highlighting the importance of verifying the effects of MV on this test.

Thus, the objective of the present study was to investigate and compare the strength response, and the neuromuscular activity of the biceps brachii and brachioradialis in isometric and dynamic contractions during the barbell curl exercise with WBV and LV. We hypothesized the LV will lead to greater neural activity by higher $\mathrm{EMG}_{\mathrm{amplitude}}$, and a greater strength response, regardless of the type of test (isometric or dynamic).

\section{Methods}

\section{Samples}

The sample consisted of 15 male volunteers, with a mean age of $25.6 \pm 3.96$ years, mean height of $178 \pm$ $3.87 \mathrm{~cm}$, and mean body fat of $13.9 \pm 1.93 \%$. Volunteers were selected from the Federal University of Minas Gerais, through personal contact, for 4 months. The sample size was calculated using the GPower 3.1 software based on data of a pilot study, following the guidelines proposed by $\mathrm{Beck}^{26}$. In this pilot study, it was noticed the EMG response during the $1 \mathrm{RM}$ test performance of the WBV condition on the biceps brachii presented the greatest values of coefficient of variation between the conditions and muscles analyzed. Therefore, the mean (M1) and standard deviation $\left(\mathrm{SD}_{1}\right)$ values of the EMG biceps brachii from the WBV during the 1RM test were used to calculate the effect size (Cohen's $\mathrm{d}^{26}$ ). For the effect size calculation, the mean (M2) and standard deviation (SD2) of the EMG values of biceps brachii during the 1RM test of NV condition was used as control values on the following equation:

$$
\text { Cohen'sd }=\frac{\text { Mean } 1-\text { Mean2 }}{\text { Standart Derivation }(\mathrm{SD})_{\text {pooled }}}
$$

where Mean 1 = biceps brachii mean EMG values of WBV values during the $1 \mathrm{RM}$ test, and the Mean $2=\mathrm{bi}$ ceps brachii mean EMG values of NV values during the $1 \mathrm{RM}$ test, and the $\mathrm{SD}_{\text {pooled }}=\sqrt{\left(\mathrm{SD}_{1}^{2}+\mathrm{SD}_{2}^{2}\right)}$. The result of Cohen's d equation (effect size $=0.25$ ) was inserted in the GPower 3.1 software. Thus, an effect size of 0.25 , power of $80 \%, \alpha=0.05$, the correlation between repeated measurements of 0.75 , three groups (NV, WBV, and LV), six measurements (1RM test, MIVC, EMG in these two tests for two muscles) were adopted for the sample size calculation.

All volunteers were regularly enrolled in a strength training program for at least six uninterrupted months, being considered as recreationally trained ${ }^{27}$. Exclusion criteria were the incidence of lesions, musculoskeletal diseases in either lower and upper limbs for the last 12 months, or any heart disease. All volunteers received complete information about the objectives and methodological procedures and signed a consent term. The local ethics committee approved this study (under the number: 240.834, year: 2013, process number: 13683413.6.0000.5149), which complied with international standards.

\section{Procedures}

Materials

In this study, a cable crossover machine was used (Pedalar $^{\circledR}$, Brazil), containing on each side 16 plates of $5 \mathrm{~kg}$. For LV application, a three-phase induction motor (WEG W22 PLUS, 2 cv, 3385 rpm, 220-380 V - Siemens $\left.{ }^{\circledR}\right)$ was used. An eccentric shaft with a pulley at the end was attached to the motor, in which the crossover cable passed around this pulley allowing performing the exercise. The motor was fixed to the ground, facing one side of the crossover, making the cable assuming a vertical trajectory between the crossover sheave and the motor. Figure 1 shows the equipment.

For the WBV application, a vibrating platform (Planet for Fitness ${ }^{\circledR}$, model PT 004 Professional - USA), adapted with a motor identical to the one used in LV was used. Both the platform and the LV motor were connected 


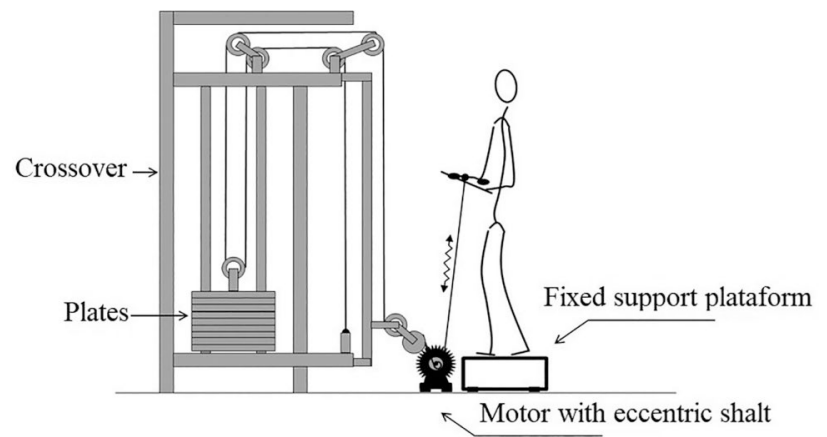

Figure 1 - Motor positioning for localized location application.

to a frequency inverter (WEG, model CFW 09). The vibratory platform was positioned close to the motor at a distance that allowed the cable goes to a vertical trajectory and parallel to the volunteer body. Figure 2 shows how WBV was performed.

The motors from LV and the vibratory platform were only switched on under LV and WBV conditions, respectively. The vibration frequency and amplitude for both cases were $26 \mathrm{~Hz}$ and $6 \mathrm{~mm}$, respectively ${ }^{21,28}$. The time of exposure to vibration was restricted to the time needed to perform the exercise. The frequency inverter was used to control the vibration frequency. The LV amplitude was determinate by the eccentric shaft, which was connected to the cable and in the WBV platform. Subjects were instructed to keep their knees flexed $\left(10^{\circ}\right)$, feet parallel, and positioned at a predetermined location to ensure a peak-topeak amplitude of $6 \mathrm{~mm}$. To verify the severity of human body exposure to vibration, the estimated vibration dose value (eVDV) was calculated from the head acceleration. The eVDV was 10.77 and 9.93 for the WBV and LV respectively. Values of eVDV greater than 17 are considered harmful to the human organism ${ }^{29}$.

To collect EMG data, surface electrodes of the $3 \mathrm{M}$ brand ( $3 \mathrm{M}$, Brazil) were used, fixed in the biceps brachii muscle, according to SENIAM project guidelines, and in the brachioradialis at the greater portion of the muscle belly (right arm), located after a voluntary contraction ${ }^{31}$. The range of motion was controlled by an electrogoniometer (Mega Electronics Ltda, Finland) with its axis of rotation fixed on the lateral epicondyle of the humerus

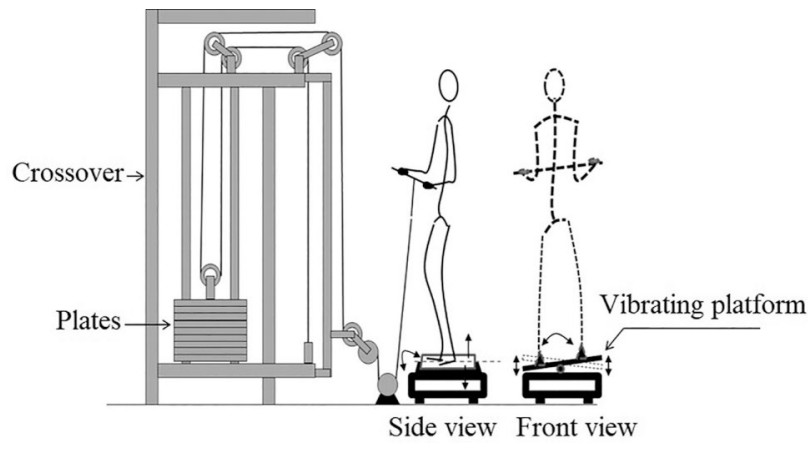

Figure 2 - Platform positioning for whole-body vibration application.

of the left arm. All devices were connected to a biomonitor (Mega Electronics Ltda, Finland - model ME6000) responsible for amplification, analog-to-digital conversion $(1000 \mathrm{~Hz})$, and signal transmission to a portable computer, with a sampling rate of $1000 \mathrm{~Hz}$. The EMG and the electrogoniometry data were recorded and analyzed using MegaWin software version 3.0 (Mega Electronics Ltda, Finland). To record the peak force during the MVIC, a load cell (Zb Staniak, Poland) with 1000 Newtons capacity, calibrated, connected to a signal amplifier and decoder (WTM 005-2T / 2P, Jaroslaw Doliriski Systemy Mikroprocesorowe, Poland) was used. The amplifier was connected to a computer interface with the program MAX5 (version 5.1, JBA, ZbStaniak, Poland), which allows analysis of the force curve as a function of time with a sampling frequency of $1000 \mathrm{~Hz}$. For both the EMG, and the electrogoniometer data, a bandpass filter with a lower limit of $26 \mathrm{~Hz}$ and an upper limit of $450 \mathrm{~Hz}$, and a $60 \mathrm{~Hz}$ band-reject filter were used.

Familiarization

The volunteers came to the laboratory on 7 different days, with, at least, $48 \mathrm{~h}$ of rest between days. On the first day, before familiarization begins, subjects performed a single set of 10 maximum repetitions in the barbell curl exercise. The weight lifted was based on the subjects experience and it was used to estimate the value for one maximum repetition (1RM), by using the equation adopted by Shaw et al. ${ }^{30}$, presented below:

$$
1 \mathrm{RM}=\frac{\text { weight lifted }}{[1.0278-(\text { number of repetitions until fail } \times 0.0278)]}
$$

After five minutes of resting, the familiarization protocol for each experimental condition (WBV, LV, and NV) was started. The familiarization protocol was composed of 2 sets with 2 repetitions at $95 \%$ of the estimated 1RM value. Three minutes rest between sets, and five minutes between each experimental condition were respected.

The barbell curl exercise constituted the bilateral flexion of the elbow, starting from the full elbow extension 
position, going to maximum elbow flexion, and returning to the initial position. To control the elbow's range of motion, a rope passing just above and close to the left shoulder of the volunteer was used, in the sagittal plane. The end of the concentric action was considered maximal when the volunteer's left fist touched the rope. Shoulder flexion was not allowed and was controlled by the evaluator's observation. The hands held a straight bar, in the supinated position, at the width of the shoulders. In all day's tests, the subjects respected the initial position, in which they remained standing on a platform, keeping the knees semi-flexed $\left(10^{\circ}\right.$ degrees of knee flexion $0^{\circ}=$ knees fully extended) and the feet parallel and positioned in a predetermined place.

Experimental sessions

The other six days were reserved for experimental sessions, consisting of the 1RM test and the MVIC test with the same exercises of familiarization for the following conditions: WBV, LV, and NV. Each condition was performed in two subsequent days, separated by an interval of exactly $48 \mathrm{~h}$. The order of conditions in the test sessions was randomized. In all test procedures, data of the surface electromyography (EMG) activity were collected. The mean values of isometric force (MVIC), 1RM, and EMG from the two days tests (each condition) were used for analysis. An interval of exactly $120 \mathrm{~h}$ between pairs of sessions of the same experimental condition was respected.

At the beginning of all experimental sessions, the maximum voluntary isometric contraction normalization test (MVICn) was performed with and without vibration. The MVICn consisted of three maximal isometric contractions lasting six seconds with five-minute rest between attempts ${ }^{17}$. During this test, the root means square electromyographic activity $\left(\mathrm{EMG}_{\mathrm{RMS}}\right)$ of the biceps brachii and brachioradialis muscles of the right arm, and the maximum peak force was recorded (window of $250 \mathrm{~ms}$ ). The highest value of the $\mathrm{EMG}_{\mathrm{RMS}}$ was used to normalize the electromyographic data, recorded during the 1RM and MVIC tests (window of $250 \mathrm{~ms}$ ). For the accomplishment of MVICn, the volunteers adopted the initial position (same as the familiarization), keeping the elbows flexed at $90^{\circ}\left(0^{\circ}=\right.$ elbow fully extended $)$, gauged using the electrogoniometer.

Respecting a 10 min resting after the MVICn, volunteers started the 1RM test in one of the study conditions (WBV, LV, or NV), adopting the same positioning and execution used during familiarization. The test consisted of five maximum attempts, with five-minute rest between each attempt ${ }^{17}$. The initial weight was $5 \%$ lower than the estimated $1 \mathrm{RM}$ value $\mathrm{e}^{32}$. The progression of the weight was gradual in the function of the subjective perception of the volunteers and evaluators. Each volunteer was instructed to perform only one repetition per attempt. Whenever the movement was performed improperly, or if the volunteer used accessory movements, the weight lifted in the previous attempt was considered the maximum weight (1RM).

After the 1RM test, respecting a 30-min interval, the MVIC test was performed in one of the study conditions (WBV, LV, or NV), and its data was used to verify the effects of MV on electromyographic activity and peak force. The procedures and positioning of the volunteers were the same as used in the MVICn tests.

\section{Statistical analysis}

Initially, the analyses of descriptive data were performed, and Shapiro Wilk tested the normality of data. The interclass coefficient correlation $\left(\mathrm{ICC}_{3,1}\right)$ and the normalized standard error of measurement (\% SEM- SEM/ mean data multiplied by 100) were calculated with data collected in sessions with the same experimental condition for EMG, MVIC, and 1RM. To analyze the ICC and SEM, the highest value of EMG, the force peak during the MVIC, and the 1RM test result, found in each of the two sessions for the same condition, were considered. Oneway ANOVAs with repeated measures with post hoc of Scott-Knott (when necessary) were used to compare the conditions. The significance level adopted as $\alpha<0.05$. Additionally, the eta-squared (n2) was also calculated as effect size $\left(\mathrm{SS}_{\text {effect }} / \mathrm{SS}_{\text {total }}\right.$, where $\mathrm{SS}_{\text {effect }}=$ sum of squares for the effect, and $\mathrm{SS}_{\text {total }}=$ total sum of squares), considering the following interpretation: $<0.06=$ small; $0.06-0.14$ $=$ moderate $;>0.14=\operatorname{large}^{32}$. All statistical procedures were performed using the software SISVAR 5.7.

\section{Results}

\section{ICC and SEM for 1RM test, MVIC, and EMG $G_{R M S}$}

Regarding the data collection reliability between day 1 and 2 for each condition (NV, LV, WBV), the $\mathrm{ICC}_{3,1}$ and normalized SEM values were, respectively, for 1RM test $=0.999$ and $1.17-1.18 \%$; for MVIC $=0.996-0.997$ and $1.00-1.40 \%$; for $\mathrm{EMG}_{\mathrm{RMS}}$ (biceps brachi and brachioradialisis) $=0.991-0.999$ and $0.7-2.6 \%$.

\section{RM EMG values}

The normalized $\mathrm{EMG}_{\mathrm{RMS}}$ values of biceps brachii during the $1 \mathrm{RM}$ test were $98.04 \pm 5.68 \%, 116.79 \pm$ $11.76 \%$, and $106.07 \pm 7.67 \%$ for $\mathrm{NV}, \mathrm{LV}$ and $\mathrm{WBV}$, respectively. According to ANOVA these values are different between conditions $\left(\mathrm{F}_{2,42}=17.362 ; \mathrm{p}<0.001\right.$; $\eta^{2}=0.452$ : large). Post hoc of Scott-Knott detected that $\mathrm{LV}$ presented greater values than $\mathrm{WBV}$ and $\mathrm{NV}$, and the WBV presented higher values than NV.

The normalized $\mathrm{EMG}_{\mathrm{RMS}}$ values of brachioradialis presented mean values of $102.56 \pm 6.60 \%, 120.47 \pm$ $11.87 \%$, and $110.90 \pm 12.74 \%$ for $\mathrm{NV}, \mathrm{LV}$ and $\mathrm{WBV}$, 
respectively. According to ANOVA these values are different between conditions $\left(\mathrm{F}_{2,42}=10.408 ; \mathrm{p}<0.001\right.$; $\eta^{2}=0.331$ : large). Post hoc of Scott-Knott detected that $\mathrm{LV}$ presented greater values than $\mathrm{WBV}$ and $\mathrm{NV}$, and the WBV presented higher values than NV. Figure 3 shows the comparisons among the conditions for both muscles.

\section{MVIC EMG values}

The normalized $\mathrm{EMG}_{\mathrm{RMS}}$ values of biceps brachii during the MVIC presented $99.94 \pm 1.90 \%, 122.09 \pm$ $12.67 \%$, and $111.15 \pm 7.21 \%$ for $\mathrm{NV}, \mathrm{LV}$ and $\mathrm{WBV}$, respectively. According to ANOVA test there were differences between the conditions $\left(\mathrm{F}_{2,42}=25.536 ; \mathrm{p}<0.001\right.$; $\eta^{2}=0.54$ : large). $\mathrm{LV}$ presented greater values than $\mathrm{NV}$ and WBV, and WBV values were higher than NV.

The normalized $\mathrm{EMG}_{\mathrm{RMS}}$ values of brachioradialis during the MVIC presented $101.01 \pm 3.30 \%, 123.30 \pm$ $11.85 \%$, and $112.20 \pm 10.33 \%$ for $\mathrm{NV}, \mathrm{LV}$ and $\mathrm{WBV}$, respectively. According to ANOVA test there were differences between the conditions $\left(F_{2,42}=21.646 ; p<0.001\right.$; $\eta^{2}=0.50$ - large). LV presented greater values than NV and WBV, and WBV values were higher than NV. Figure 4 shows the comparisons among the conditions for both muscles.

\section{$1 R M$}

The mean weight lifted during the $1 \mathrm{RM}$ test in NV, $\mathrm{LV}$ and WBV were $69.03 \pm 8.15 \mathrm{~kg}, 69.17 \pm 8.12 \mathrm{~kg}$ and $69.6 \pm 8.12 \mathrm{~kg}$, respectively. According to ANOVA, there was no difference in the $1 \mathrm{RM}$ values between the condi- tions $\left(\mathrm{F}_{2,42}=0.020 ; \mathrm{p}=0.9803 ; \mathrm{\eta}^{2}=0.001\right.$ : small $)$ (Figure 5).

\section{MVIC test}

The isometric peak force values during the MVIC test were $459.33 \pm 38.94 \mathrm{~N}, 498.87 \pm 49.58 \mathrm{~N}$, and 478.42 $\pm 43.14 \mathrm{~N}$, respectively for NV, LV and WBV. According to ANOVA test there were no differences between conditions, only a trend $\left(\mathrm{F}_{2,42}=2.983 ; \mathrm{p}=0.061 ; \mathrm{\eta}^{2}=0.12\right.$ : moderate) (Figure 6).

\section{Discussion}

The present study aimed to compare the EMG response and the strength performance in dynamic and isometric tests performed with $\mathrm{LV}, \mathrm{WBV}$, and NV. We hypothesized the LV would lead to a greater strength response and neural activity. According to the results, the EMG response of the biceps brachii and brachioradialis during the 1RM and MVIC tests presented values significantly higher in LV in relation to the WBV and NV. Thus, the hypothesis of the present study was partially confirmed. The 1RM test performance and the MVIC values were not different between conditions (LV, WBV, and NV). These results indicate that the application of MV did not improve the strength performance.

However, the results showed a significant increase in the $\mathrm{EMG}_{\mathrm{RMS}}$ in either muscle when the MV was applied. Some studies have also demonstrated an increase in EMG during MV application compared to exercises performed
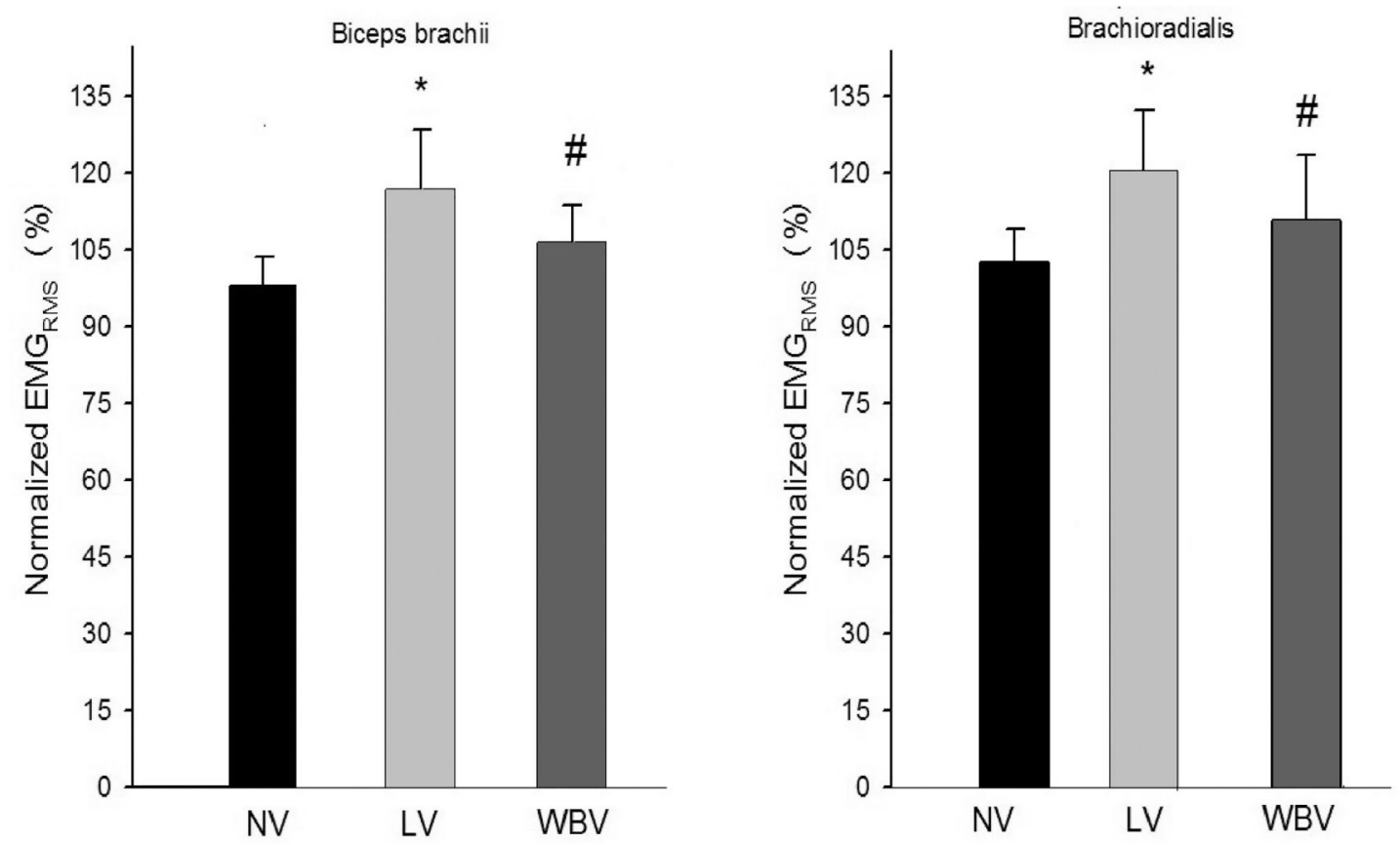

Figure 3 - Normalized $\mathrm{EMG}_{\mathrm{RMS}}$ of the brachii and brachioradialis biceps during the $1 \mathrm{RM}$. NV = No vibration; $\mathrm{LV}=\mathrm{Local}$ Vibration; WBV $=$ wholebody vibration. Vertical lines = standard errors. *: Greater than NV and WBV. \#: Greater than NV. Significance level at $\alpha<0.05$. test. 

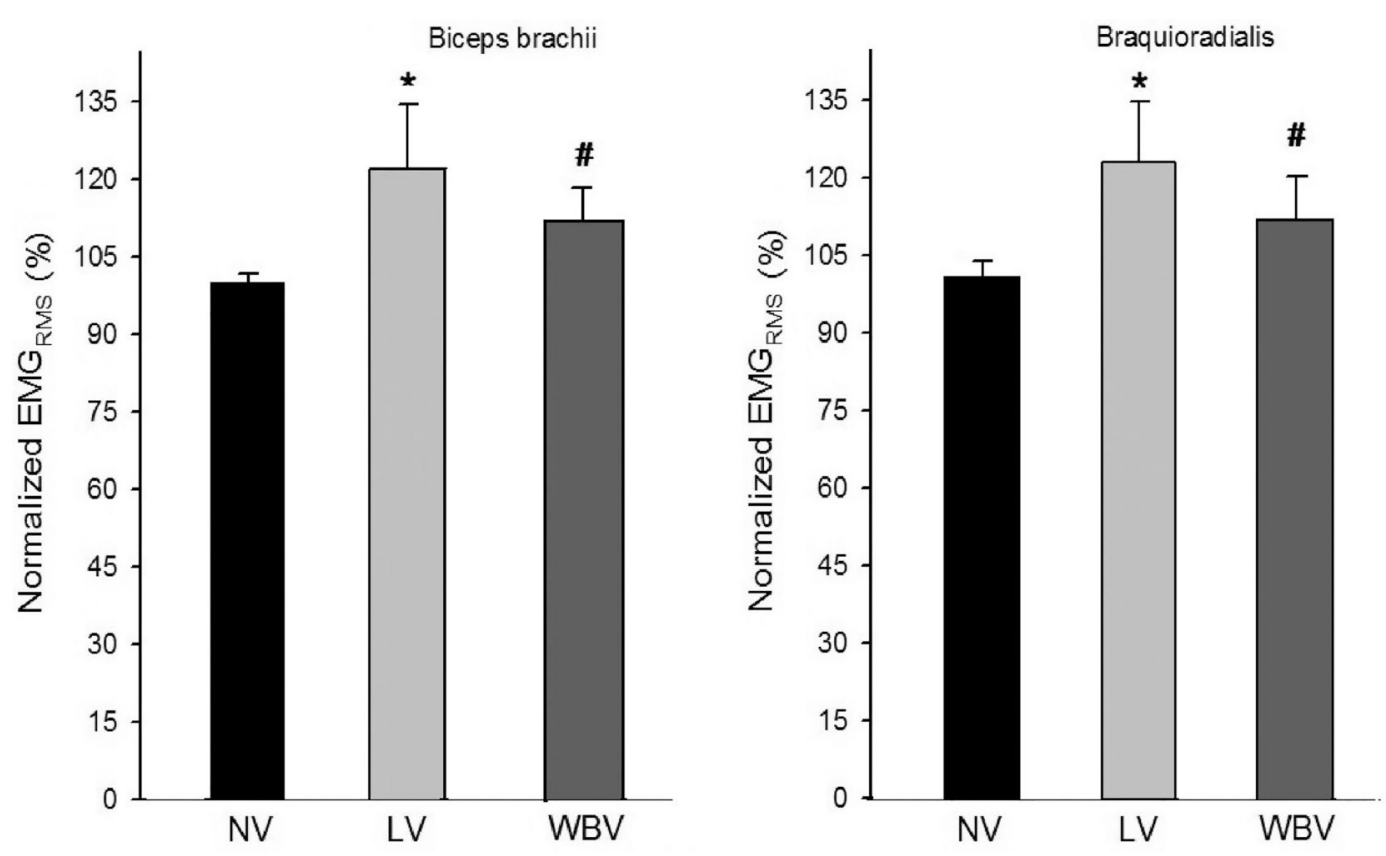

Figure 4 - Normalized EMG $\mathrm{RMS}_{\mathrm{R}}$ of the biceps brachii and brachioradialis during the MVIC. MVIC = maximum voluntary isometric contraction. $\mathrm{NV}=$ No vibration; $\mathrm{LV}=$ Local Vibration; WBV = whole-body vibration. Vertical lines = standard errors. *: Greater than NV and WBV. \#: Greater than NV. Significance level at $\alpha<0.05$.

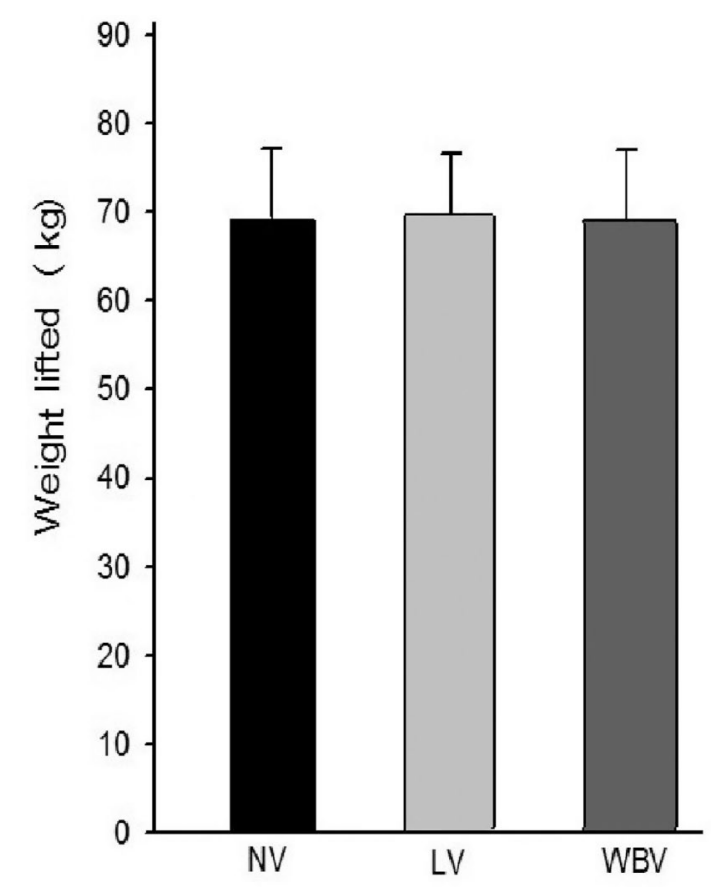

Figure 5 - Weight lifted during the $1 \mathrm{RM}$ test. NV = No vibration; $\mathrm{LV}=$ Local Vibration; $\mathrm{WBV}=$ whole body vibration. Vertical lines $=$ standard errors.

without vibration ${ }^{34,35}$. Cardinale and Bosco ${ }^{36}$ found that four sets of $60 \mathrm{~s}$ of WBV, with the frequency of $30 \mathrm{~Hz}$ and amplitude of $10 \mathrm{~mm}$, were able to significantly increase the $\mathrm{EMG}_{\mathrm{RMS}}$ in the muscles of the upper limbs during the elbow flexion exercise performed dynamically. Hazzel, Jakobi, and Kenno ${ }^{37}$ found an increase in EMG in the muscles of the lower and upper limbs. In this study, squat and elbow flexion exercises were performed, both isometric and dynamic, with frequencies of $25,30,35,40$, and $45 \mathrm{~Hz}$. The presence of tonic vibration reflex may justify the higher EMG activity of the muscles exposed to vibration $^{13,36}$. Thus, perhaps the MV may have interfered with the EMG values and consequently the interpretation of the results. Notwithstanding, no study that compared the EMG response in activities performed with LV, and WBV were found. We suggest that new studies investigate this possibility.

During the WBV, the vibration impulse may have dissipated during its transmission through the body tissues $^{12}$. The oscillation amplitude of the elbow joint in the WBV condition may have been smaller in comparison to the LV, generating smaller accelerations. Greater amplitude of displacement is associated with greater tonic vibration reflex and consequently, activation of several muscle spindles ${ }^{11}$. This phenomenon may explain the lower values of $E M G_{R M S}$ found during the WBV when compared to the LV that received the same frequency of vibration.

The MVIC tests did not show significant differences between the experimental conditions. Oliveira et al. ${ }^{38}$ corroborate these results, as they verified that the application of MV, in the frequencies of 10,20,30, and $40 \mathrm{~Hz}$ was not able to increase the strength production in trained individuals. According to Oliveira et al. ${ }^{38}$, the fact that MV does 


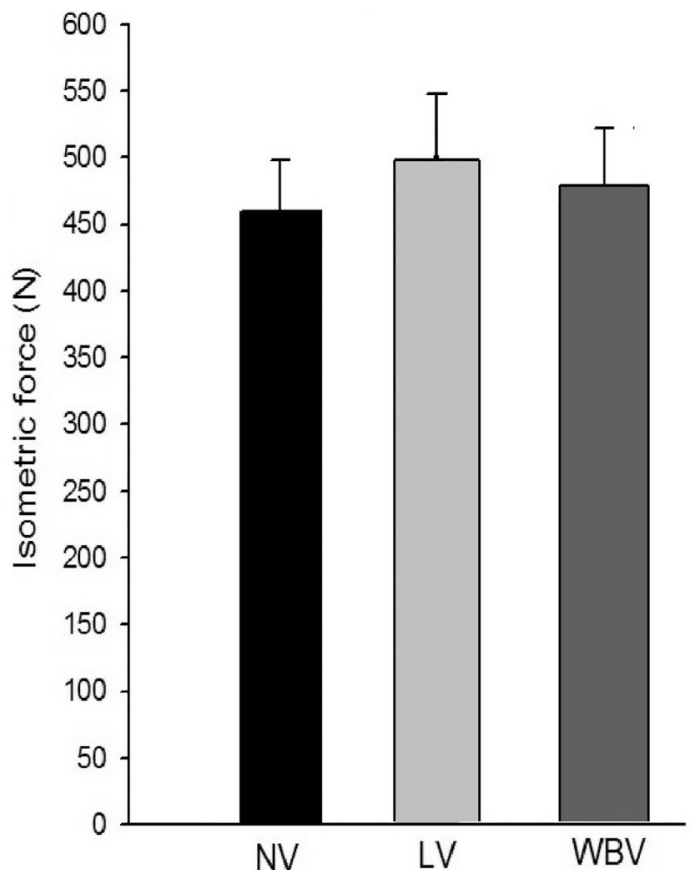

Figure 6 - Comparison of maximum isometric voluntary contraction. NV $=$ No vibration; $\mathrm{LV}=$ Local Vibration; $\mathrm{WBV}=$ whole body vibration . Vertical lines $=$ standard errors

not increase strength in MVIC tests may be related to individual characteristics, such as the level of experience in training with vibration and the MV settings. Still, Warman, Humphrtes, and Purton ${ }^{39}$ also did not find significant differences in the isometric strength with or without the MV. The non-increase in the MVIC indicates that the higher EMG generated by the vibratory stimulus was not sufficient to recruit additional motor units that promoted greater force production in the specific task evaluated. The angle at which the MVIC test is performed can also influence the transmissibility of the vibratory impulse since changes in the angle interfere with the tension present in the target muscle ${ }^{39}$. In the present study, only the $90^{\circ}$ angle of elbow flexion was used during the test, and future studies are needed to assess the effect of MV application at different angles during the MVIC.

No significant differences were found in the 1RM tests between conditions. Hammer, Joshua, and Linton ${ }^{40}$ also found no significant differences in the 1RM test with and without MV application. According to these authors, the vibratory stimulus may not have been specific enough to promote increases in strength in trained individuals. Cochrane ${ }^{41}$ also did not find an increase in the concentric strength in the elbow flexion exercise with MV application. However, the findings of the present study oppose the result presented by the previous studies ${ }^{18,19,35}$, which found a positive effect of MV application in the 1RM tests in upper and lower limb exercises. Such divergence may be since the response to the vibratory stimulus depends on aspects such as the time of exposure to vibration ${ }^{42}$, the frequency of vibration ${ }^{9,10}$, the range of displacement ${ }^{11}$, and/or type of muscle action ${ }^{10}$.

It was expected a greater strength performance during MVIC and 1RM tests with MV application because of the presence of tonic vibratory reflex due to muscle stretches that occurred throughout contractions with MV ${ }^{43}$. According to Issurin et al. ${ }^{7}$, Torniven et al. ${ }^{43}$, and Mileva et al. $^{18}$, the tonic vibratory reflex may improve the synchronization firing discharges and causing a larger number of motor-units recruitment, leading to greater strength production. However, the result of this study does not corroborate this reasoning. Perhaps, the higher EMG response for MV application was not sufficient to promote significantly higher strength production. Other MV configurations can be effective to generate higher strength performance. This suggests that other studies with different MV parameters could be conducted to respond to this literature gap.

Some studies adopt the result of the 1RM test, performed without the application of vibrations, as a reference for the prescription of training intensity with and without the application of mechanical vibrations ${ }^{7,25}$, therefore the results of the study may contribute to decisions regarding of application of VM or the type of VM in future works or the physical training. The limitations of the study, we can mention the need of using filters in the EMG signal, aiming to exclude the noise from cable vibrations; and the non-measurement of the cross-talks effect. Additionally, the results found in the present study should be limited to the vibration parameters. Further studies are required using different vibration parameters to verify the effects of MV on strength development.

\section{Conclusion}

The MV application resulted in higher EMG activity in the 1RM and MVIC tests, The LV promotes higher EMG than WBV. However, the MV application was not able to increase the strength production compared to the non-application of MV in the 1RM and MVIC tests.

\section{References}

1. Bosco C, Cardinale MC, Tsarpela O, Madella A, Tihanvi J, Viru A. Adaptive responses of human skeletal muscle to vibration exposure. Clin Physiol. 1999;19(2):183-7.

2. Jordan MJ, Norris SR, Smith DJ, Herzog W. Vibration training: an overview of the area, training consequences, and future considerations. J Strength Cond Res. 2005;19 (2):459-66. doi.

3. Marín PJ, Rhea MR. Effects of vibration training on muscle. Strength: a meta-analysis. J Strength Cond Res. 2010;24 (2):548-56. doi. 
4. Rittweger J. Vibration as an exercise modality: how it may work, and what its potential might be. Eur J Appl Physiol. 2010;108(5):877-904. doi.

5. Lisón-Párraga JF, Martí-Salvador M, Harto-Cea D, JuliánRufino P, Valero-Navarro J, Vera-García FJ, et al. Efectos de un entrenamiento vibratorio sobre la actividad del rectus abdominis y sobre la transmisión de aceleraciones durante la realización de un puente frontal. Rev Int Cienc Deporte. 2012;29(8):127-41. doi.

6. Martín-Santana E, Hernández-Sánchez S, Herrero-Alonso AJ, García-López. D. Effects of static stretching and wholebody-vibration during warm-ups on bench-press kinematics in males and females' college-aged. Rev Int Cienc Deporte. 2015;42(11):348-59. doi.

7. Issurin VB, Liebermann DG, Tenenbaum G. Effect of vibratory stimulation training on maximal force and flexibility. J Sports Sci. 1994;12(6):561-6. doi.

8. Couto BP, Silva HR, Barbosa MP, Szmuchrowski LA. Chronic effects of different frequencies of local vibrations. Int J Sports Med. 2012;33(2):123-9. doi.

9. Cardinale M, Lim J. Electromyography activity of vastus lateralis muscle during whole-body vibrations of different frequencies. J Strength Cond Res. 2003;17(3):621-4.

10. Issurin VB. Vibrations and their applications in sport. $J$ Sports Med Phys Fit. 2005;45(3):324-36.

11. Cochrane DJ. The potential neural mechanisms of acute indirect vibration. J Sports Sci Med. 2011;10(1):19-30.

12. Luo J, McNamara B, Moran $\mathrm{K}$. The use of vibration training to enhance muscle strength and power. Sports Med. 2005;35 (1):23-41. doi.

13. Martin BJ, Park HS. Analysis of the tonic vibration reflex: influence of vibration variables on motor unit synchronization and fatigue. Eur J Appl Physiol. 1997;75(6):504-11. doi.

14. Rønnestad BR, Holden G, Sammøy LE, Paulsen G. Acute effect of whole-body vibration on power, one-repetition maximum, and muscle activation in powerlifters. J Strength Cond Res. 2012;26(2):531-9. doi.

15. Hagbarth KE, Eklund G. The effects of muscle vibration in spasticity, rigidity, and cerebellar disorders. J Neurol Neurosur. Psychiatry. 1968;31(3):207-13.

16. Bosco $\mathrm{C}$, Cardinale $\mathrm{M}$, Tsarpela $\mathrm{O}$. Influence of vibration on mechanical power and electromyogram activity in human arm flexor muscles. Eur J Appl Physiol. 1999;79(4):306-11. doi.

17. Drumond MDM, Couto BP, Augusto IG, Rodrigues SA, Smuchrowski LA. Effects of 12 weeks of dynamic strength training with local vibration. Eur J Sport Sci. 2014;14 (7):695-702. doi.

18. Mileva KN, Naleem AA, Biswas SK, Marwood S, Bowtell JL. Acute effects of a vibration-like stimulus during knee extension exercise. Med Sci Sports Exerc. 2006;38(7):131728. doi.

19. Poston B, Holcomb WR, Guadagnoli MA, Linn LL. The acute effects of mechanical vibration on power output in the bench press. J Strength Cond Res. 2007;21(1):199-203. doi.

20. Silva HR, Couto BP, Szmuchrowski LA. Effects of mechanical vibration applied in the opposite direction of muscle shortening on maximal isometric strength. J Strength Cond Res. 2008;22(4):1031-6. doi.

21. Drummond MDM, Couto BP, Oliveira MP, Szmuchrowski LA. Effects of local vibration on dynamic strength training. J Strength Cond Res. 2021;35(11):3028-34. doi.

22. Burke D, Hagbarth KE, Löfstedt L, Wallin BG. The responses of human muscle spindle endings to the vibration of non-contracting muscles. J Physiol. 1976;261(3):673-93. doi.

23. Lienhard K, Vienneau J, Nigg S, Friesenbichler B, Nigg B. Older adults show higher increases in lower-limb muscle activity during whole-body vibration exercise. J Biomech. 2017;8(52):55-60. doi.

24. Hunter SK, Duchateau J, Enoka RM. Muscle fatigue and the mechanisms of task failure. Exerc Sport Sci Rev. 2004;32 (2):44-9.

25. Rønnestad BR. Acute effects of various whole-body vibration frequencies on 1RM in trained and untrained subjects. J Strength Cond Res. 2009;23(7):1031-6. doi.

26. Beck T. The importance of a priori sample size estimation in strength and conditioning research. J Strength Cond Res. 2013;27(8):2323-37. doi.

27. Rhea M. Determining the magnitude of treatment effects in strength training research through the use of the effect size. J Strength Cond Res. 2004;18(4);918-20.

28. Cochrane DJ, Stannard SR. Acute whole-body vibration training increases vertical jump and flexibility performance in elite female field hockey players. Br J Sports Med. 2005;39(11):860-5. doi.

29. Abercromby A, Amonette W, Layne C, McFarlin B, Hinman M, Paloski W. Vibration exposure and biodynamic responses during whole-body vibration training. Med Sci Sports Exerc. 2007;39(10):1794-1800. doi.

30. Shaw BS, Shaw I, Brown GA. Comparison of resistance and concurrent resistance and endurance training regimes in the development of strength. J Strength Cond Res. 2009;23 (9):2507-14. doi.

31. Kang T, Seo Y, Park J, Dong E, Seo B, Had E. The effects of elbow joint angle change on the elbow flexor muscle activation in the pulley with weight exercise. J Phys Ther Sci. 2013;25(9):1133-6. doi.

32. Cohen J. Statistical Power analysis for the behavioral sciences. 2nd ed. Hillsdale, Lawrence Erlbaum Associates Publishers; 1988.

33. Delecluse C, Roelants M, Verchueren S. Strength increase after whole-body vibration compared with resistance training. Med Sci Sports Exerc. 2003;35(6):1033-41. doi.

34. Verschueren SMP, Machteld RM, Delecluse C, Swinnen S, Vanderschueren DBS. Effect of 6-month whole body vibration training on hip density, muscle strength, and postural control in postmenopausal women: a randomized controlled pilot study. J Bone Miner Res. 2004;19(3):352-9. doi.

35. Cardinale M, Bosco $\mathrm{C}$. The use of vibration as an exercise intervention. Exerc Sport Sci Rev. 2003;31(1):3-7.

36. Hazell TJ, Jakobi JM, Kenno KA. The effects of wholebody vibration on upper-and lower-body EMG during static and dynamic contractions. Appl Physiol Nutr Metab. 2007;32(6):1156-63. 
37. Oliveira MP, Menzel HJK, Drummond MDM, Albuquerque SL, Szmuchrowski LA, Serpa TKF, et al. Efeito agudo da aplicação de vibração de corpo inteiro na força muscular de membros superiores. J Phys Educ. 2019;30:e3022. doi.

38. Warman G, Humphries B, Purton J. The effects of timing and application of vibration on muscular contractions. Aviat Space Environ Med. 2002;73(2):119-27.

39. Hammer R, Linton JT, Hammer AM. Effects of heavy squat training on a vibration platform on maximal strength and jump performance in resistance-trained men. J Strength Cond Res. 2018;32(7):1809-15.

40. Cochrane DJ. Does muscular force of the upper body increase following acute, direct vibration? Int J Sports Med. 2016;37(7):547-51. doi.

41. Mischi M, Rabotti C, Cardinale M. Analysis of muscle fatigue induced by isometric vibration exercise at varying frequencies. Conference Proceedings: Annual International Conference of the Engineering in Medicine and Biology Society. 2012;2012:6463-6. doi

42. Opplert J, Genty JB, Babault N. Do stretch duration affect muscle mechanical and neurophysiological properties? J Sports Med. 2016;37(9):673-9.
43. Torvinen S, Kannu P, Sievänen H, Järvinen TA, Pasanen M, Kontulainen S, et al. Effect of a vibration exposure on muscular performance and body balance. Randomized crossover study. Clin Physiol Funct Imaging. 2002;22(2):145-52. doi.

\section{Corresponding author}

Aler Ribeiro de Almeida. Universidade Federal de Minas Gerais, Belo Horizonte, MG, Brazil.

E-mail: aler.ribeiro@hotmail.com.

Manuscript received on June 16, 2021

Manuscript accepted on September 27, 2021

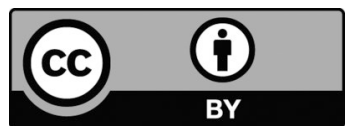

Motriz. The Journal of Physical Education. UNESP. Rio Claro, SP, Brazil - eISSN: 1980-6574 - under a license Creative Commons - Version 4.0 